\title{
The Role of Territorial Promotion Agencies in the Creation of a Valuable Tourist Experience. An Italian Case History
}

\author{
Arianna Di Vittorio \\ Associate Professor of Marketing, Dept of Economics, \\ Management and Business Law, University of Bari, Bari, Italy
}

Doi:10.19044/esj.2018.v14n29p106 URL:http://dx.doi.org/10.19044/esj.2018.v14n29p106

\begin{abstract}
With the passage of time, the offer made by tourism companies has undergone important changes, becoming more and more configured as a unique and memorable consumer experience, able to activate the sensory system of the consumer and to stir up emotions. The experiential marketing ${ }^{27}$ uses the experiences lived by consumer as marketing tool so as to make the consumer perceive a higher added value, thanks to the involvement of the senses and emotions. Also within the tourism sector, the need to cope with the new needs of tourists led the companies on the road to experiential differentiation.

In today's society, consumption is no longer a private and personal act, but a real "social event" in the sense that a product is purchased not so much for its functional value, as for the meaning it assumes for those who use it or consume it and for its own social relationships. The consumer experience therefore generates a noticeable involvement for consumer and for its own social relations: the individual seeks, for this reason, products and services with a symbolic value, that allow him to fully manifest his personality. "To consume means to satisfy one's own needs, but also to create and maintain social relationships" (Douglas \& Isherwood, 1989).

The paper focuses on the role of Tourist Promotion Agencies, particularly on the Agency "Tourism Imperial Apulian", reference subject for marketing, reception and promotion of Local Tourist System "Puglia Imperiale", and new reference for creation of a quality tourist experience.
\end{abstract}

27 Writing about experiential marketing means the particular sector of marketing that concentrates its own attention on the perceived and proved experience by consumer during the choice process and following purchase. The goal is to concentrate itself about the consumer's perception, to act directly on the leverage points that allow a greater conversion of intentions for sale. 
The methodology used in the paper is a descriptive empirical analysis; after a view on the variables important to create a valuable experience for tourists and a statistical reflection on the data related to the incoming in Puglia from 2007 to 2014, the Author describes the strategies adopted in the case history.

This empirical analysis aims to confirm the promotional validity of the "Puglia Imperiale" Tourist Agency and, above all, to witness the creation of a new territorial identity brand evolved into a real tourism product, through the activity of a Management Agency of the destination.

Keywords: Tourism, Local System, promotion, experiential approach

\section{The tourist consumption as experience}

«According to the most common interpretation» (Addis, 2007), the customer experience is divided into two principal components:

- the attribution of the sense of the individual to the lived interaction;

- $\quad$ interaction between the individual and the bidding system.

In order that we can talk about consumer experience, it is necessary a beneficial relationship between consumer and company, in such a way that the individual can be involved and is able to interpret the interaction that takes place during the consumer experience. The nature of consumer experience is complex, because consumer and his choices regarding what to consume are influenced by emotional factors connected to the experiential vision.

The interaction can be physical, cognitive and emotive and has to be realized in four moments, as Arnould, Price and Zinkhan affirm:

- The pre-purchase experience during which, thanks to internal and external stimulus, the consumer perceives the need of travelling and on whose basis there is the tourist motivation ${ }^{28}$. The stimulus generates in the individual a tension, a discomfort, a need of consumption that induces an individual to look for the tourist information necessary to satisfy it (Kotler, Bowen \& Makens, 2010): in this phase the potential tourist-consumer analyzes leaflets, catalogues, asks the acquaintances for advice, so as he can evaluate available alternatives. It is important to create already interaction between company and consumer since this moment, by attracting the consumer's attention thanks to efficient communication and distribution policies.

28 The tourist motivation is episodic, discretional, dynamic, oriented towards future, in continuous evolution and at the same time socially influenced. Therefore, it includes all those conscious and no conscious factors that induce an individual to travel. 
- $\quad$ The purchase experience during which the individual expresses the decision of purchase. This phase "constitutes the most studied experiential moment by means of its high efficacy and of several possibilities of planning and management of interaction" (Addis, 2007), in which the company can exploit at its best the retail management, pointing to visual merchandising, atmosphere and personnel.

- $\quad$ The experience at the heart of consumption, during which the travel experience is shown and the use in loco of tourist service. It is just in this phase that the company will have to be able that the individual can reach the top level of involvement, thanks to the whole of sensations, emotions generated by interaction between individual and tourist product. The company will have to rely on the product and ancillary services.

- $\quad$ The reified experience linked to the fact that for the individual the experience does not end up with the consumption, but it continues through memory, thanks to memories, and souvenir. The company's task in this phase must be exactly that of contributing to keep the experience still alive relying on the brand image and on merchandising so as to make tangible the experience itself and transmit the memory.

A good experience, to be considered as such, must be "unforgettable" (Pine \& Gilmore, 1999) that is able to stir up emotions, involve all the consumer's senses and produce important transformations. This is possible through the staging of "personal" and "memorable" events that can charm consumers and let them come back. The more emotions linked to consumption are, the more valuable that experience will be able to create, thanks to interaction between individual and tourist product.

In the experiential approach by Robert F. Lauterboun the attention moves from the product to the consumer. In fact, its " $4 \mathrm{Cs}$ " model is based on the following variables:

- $\quad$ Costumer need: leverage used above all in the start phase of new products because it has the utility of understanding the consumer's needs, the products and ancillary services that can able to satisfy it, even by virtue of products offered by competitors;

- $\quad$ Cost to the consumer: leverage that allows to determine the consumer's availability to pay, so as to be satisfied even from a financial point of view;

- $\quad$ Convenience: leverage of consumer's ease that allows to use the most convenient distributive modalities for the consumer;

- Communication: communicative leverage that allows to implement a communication oriented to consumer, with the aim to create a durable link with client. 
Moving the object of interest from product to consumer implies a new idea of consumption, meant above all as experience.

Therefore, the experiential marketing is based on a type of consumption, different that in the past, because it does not aim to the mere satisfaction of consumer's needs, but it has as goals his involvement, his satisfaction, the reinforcement of links with other individuals, thanks to the indispensable use of emotions. Rationality leaves place to a whole set of emotional factors that characterize the experiential purchase and impact on individual's perceptions, giving life to an experience with a high emotive content.

\section{Variables to create a valuable experience}

\section{The variables related to the brand}

In this macro-category of managerial leverages, we find all the proposals that the company puts in act to constitute its own purchase experience.

First of all, the company can resort to hedonic content of product: the "hedonic or experiential products constitute driver of success experiences; generally because of their high intrinsic emotional content". Music, art, aesthetic products constitute examples of hedonic content products, that are generally purchased by consumer because of the emotions that their consumption or use are able to transmit. The more emotions the product is able to generate, the greater its hedonic content will be. Within the tourism sector, the quality is a strictly connected concept to the intensity of emotions lived during the tourist experience, so much so that we can talk about "emotional quality" 29 in this regard.

The last variable of this macro-category is constituted by the theme of bidding system, a symbolic benefit on which company can concentrate the brand management policies. Through the creation of a well defined symbolic reality, in fact, it is possible to increase the client's perceived value, either in terms of variety of the offer or in terms of alternatives selection.

\section{The variables related to context}

In this macro-category we find all leverages that are able to influence the context in which the individual and the company's bidding system interact.

For context we mean above all the environmental dimension, "truths' place of meeting between demand and offer" (Addis, 2007). The variables referred to the environmental dimension are the physical environment and the

${ }^{29}$ The concept of "emotional quality" should not be confused with that of "perceived quality" by tourist that limits to an evaluation of company quality seen from the demand side. The "emotional quality" is linked to the canons of western culture, that is to the desire to know and enjoy different realities and to the desire to escape "in time" from one's own reality. 
virtual one. The physical environment is constituted by places where the purchase and the consumption of experiential products occur. The creation of these spectacular contexts requires investments of not indifferent resources, but the experiential function, attributed to it, is able to generate a valuable experience for those who attend them.

In addition to the environmental dimension, it is possible to rely on the social dimension, that is on the role that the social context plays, in the creation of a consumption experience. In this sense, the social benefits assume importance, and that is all those values that take hold in a given social context, and that are able to influence the consumption processes; it is those meanings that can be attributed to consumption and that allow consumer to communicate to others his social and cultural belonging.

\section{The variables related to individual}

One first variable is constituted by reasons that push consumer to purchase a determined consumption offer and to get involved in the consumption experience that derives from it. The reasons that explain the consumer's consumption behaviour can be countless, therefore it is up to the company to identify the principal reasons linked to its own offer and monitor them over time.

Another group of variables is generated by the individual's personality. It is about the «big five, that is the individual's trend to emotional instability, to extroversion versus introversion, to be open to experiences, the propensity to be condescending rather than antagonistic, to be conscientious rather than to have no directions»).

At last, also the mood with which a subject takes part to an experience constitutes an element, able to affect its own perceptions and its own attitudes. Besides, calling to the memory the lived experiences, the individual can be able to prove the same sensations that have crossed his mind when he has materially lived the experience. It is fundamental, therefore, that companies generate, through their own experience offers, a sensation of pleasure and satisfaction as great as possible.

\section{An Italian case history (Italy): "Puglia Imperiale" - Apulian Tourist Promotion Agency}

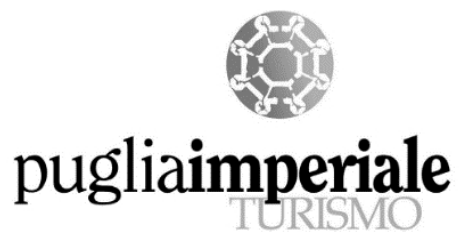

The methodology used for this case history is a descriptive empirical analysis. After an analysis on the variables that are important to create a 
valuable experience for tourists and a statistical reflection on the data related to the incoming in Puglia from 2007 to 2014, the paper confirms the promotional validity of the "Puglia Imperiale" Tourist Agency and, above all, it confirms the creation of a new territorial identity brand evolved into a real tourism product, through the activity of a Management Agency of the destination.

Brand management activities usually used for companies, with appropriate and necessary application solutions, can also be used for the enhancement of tourist destinations through territorial tourism communication and destination branding.

Tourist destinations are examined by the systemic approach, underlining that they act within wider territorial systems and that distinguish themselves from simple places because they qualify as tourism supply and production systems capable of setting up tourism products and to attract not only spontaneous tourist client flows.

The adoption of the systemic perspective also highlights a series of critical issues in the management of territorial systems with specific implications on territorial and tourist brands. The specificity of destination branding is determined by the complexity of the elements that must be considered during the design phase, considering that the success of the initiative depends on the ability of the territorial decision makers to build a consonance between the territory brand and the corporate and network brands.

\subsection{The Apulian tourist scenario of the last years}

At the presentation conference about the comparison on the Strategic Tourist Plan of Apulia Region 2016-2025, «Puglia 365», one of the key subject has been the analysis of opportunities and weaknesses of Apulian market. Observing, in fact, the incoming data in Apulia since 2007 to 2014, it is possible to notice:

- internationally, an increase of 55\% as regards the arrivals and of $58 \%$ as regards the presences;

- nationally, instead, the data show an increase of arrivals and presences respectively equal to $12 \%$ and to $7 \%$.

The data (Ejarque, 2016) show how the international arrivals in the last ten years have increased much less than those of the rest of the world (Fig.1). The data show, in fact, that in the last ten years Italy has lost 25 million visitors with an economical impact of about 18 billion euro. Besides, observing data, that highlights the weight of the different tourist products on the whole amount of arrivals in Apulia, we notice how 54\% of tourists who come in Apulia has the tourist product "seaside" as a goal. 
Fig.1. Number of international tourists' arrivals in the Italian region of Apulia from 2009 to 2015 (in 1,000s)

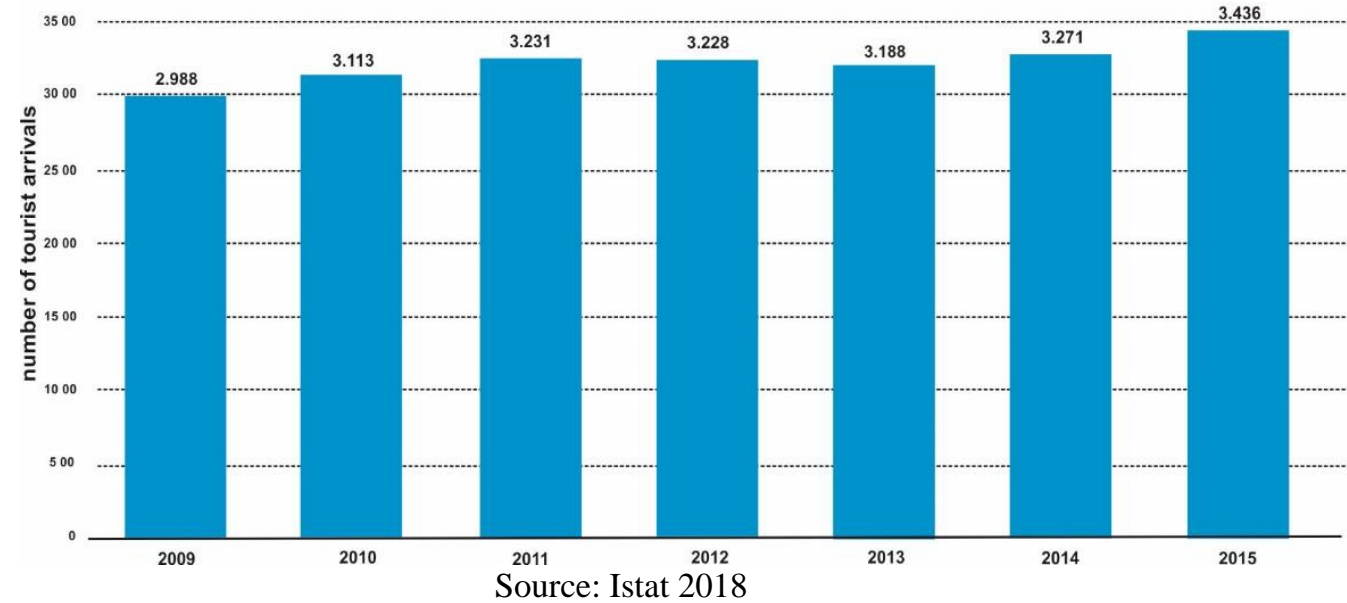

According to Josep Ejarque, among the obstacles to which destination Apulia has had to face up, we find:

- $\quad$ a crowded, more and more competitive market;

- a general myopia that is expressed in the tendency to compete all in the same markets, in the same proposals and in the same operators;

- $\quad$ a distorted view of reality: the most used approach is to think about his own point of view, without caring about what the tourist actually likes;

- «showcase destinations» (Ejarque, 2016) that are territories, monuments, history, without thinking that tourist prefers to touch with hand all that the destination offers; desired effects.

an aggressive communication that does not always have the

The tourist is "an indisputable sovereign of the tourist market": therefore the tourist destination have had to change their modus operandi relying on the tourism product, on the promotional marketing, on the destination reputation, on the customer's satisfaction, on the destination's hospitality and atmosphere. Today the success key is based on the differentiation: the destination must be seen no more as an administrative space, but as a space of experiences and consumption within which we find a tourist who decides the extension, the fruition and the experiential dimension of it.

In fact, Ejarque asserts that the fundamental criterion that guides those who operate in the tourist sector must be that of "building unique experiences, coherent and accessible to consumer". The destination must therefore be 
configured as a whole of territories that constitute different consumption's choices. Tourism is constituted, above all by tourist product, essential element for positioning on the market. To be a good destination means to have a good product and to be able to promote unique tourist experiences.

\subsection{The local tourist system "Puglia Imperiale"}

The Agency "Puglia Imperiale Turismo" was born during the second activity phase of North Barensis "Ofantino" Territorial Pact (PTO). The North Barensis "Ofantino" Territorial Pact includes the municipalities of Andria, Barletta, Bisceglie, Canosa di Puglia, Corato, Margherita di Savoia, Minervino Murge, San Ferdinando di Puglia, Spinazzola, Trani and Trinitapoli and it has been promoted by a large public-private local partnership and sustained by European Commission (Dall'Ara \& Morandi, 2006). Its task is to promote the territory's development through the valorization of historic-cultural resources and local environments and through the promotion of hospitality activity. Since 2003, the PTO has given life to the APIT, the Agency "Puglia Imperiale Turismo" with the goal to generate new management models of tourism and hospitality and to integrate public subjects with the private ones.

So «Puglia Imperiale has become synonymous and symbol of a great local system action» (Buongiorno, 2015) with the purpose of creating a new destination tourist product, through the management of a Local Tourist System (STL). Law nr. 135 of 2001, reform of national tourism legislation, Art. 5 defines the local tourist systems as "omogeneous or integrated tourist contexts, including territorial areas belonging even to different regions, characterized by the integrated offer of cultural, environmental goods, and of tourist attractions, included the typical products of agriculture and local crafts, or by the widespread presence of single or associated tourism companies".

The local Tourist Development Plan constitutes the basis of "Puglia Imperiale" System, because it has the precious function of organizing the territory of Puglia Imperiale so as to be able to offer "defined and recognizable tourism occasions and experiences for the presence of several resources". The area of Puglia Imperiale is located at the center of Apulia and includes territory's parts in which it is possible to find the traces left by Emperor Federico II of Svevia: it is about eleven municipalities located around Castel Del Monte, castle declared UNESCO heritage, which are founding an important alternative to the Apulian tourism we witnessed a few years ago. 
Fig. 2. The reason "why" of DMO

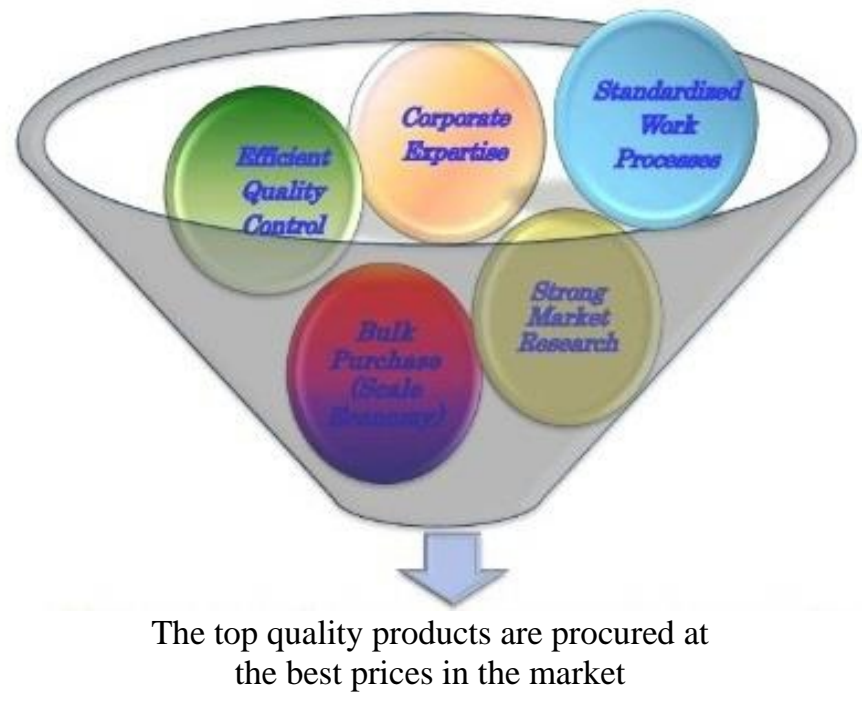

Source: Dall'Ara \& Morandi (2006)

A local tourist system allows, through its activities, to evaluate the resources, to improve the infrastructures and services, to develop the company system, through the development of offer quality (Fig.2). In fact, during 2005 the Agency "Puglia Imperiale Turismo" was constituted mixed consortium company with limited liability, with functions of Destination Management Organization: it is about a company that deals with marketing, hospitality and promotion of Local Tourism System Puglia Imperiale. «The relationship with the Tourism System is bidirectional: STL entrusts to APIT the task of elaborate and manage the Plan of local tourism development (PSTL), supplying to the same Agency the indications and recommendations derived from its own analysis, comparison and processing activity».

\subsection{The mission of Puglia Imperiale Tourism}

The Agency Puglia Imperiale Tourism is born with the goal of creating the Local Tourist System Puglia Imperiale. Creating a system implies that there is awareness among the local subjects of their interdependence; but, above all, it aims to enhance the identity and resources of territory, to guarantee a qualitatively high and original offer to potential tourists.

The Agency also performs some strategic functions:

- $\quad$ design of offer packages;

- maintaining relations with public and private entities that make up the system;

- $\quad$ collecting and processing data concerning demand, supply and cultural tourist heritage; 
- $\quad$ press office and communication activities through newspapers, magazines, website, etc.

The Agency's activity is, therefore, aimed at the public administration, at private operators and at final users. Objective is to make sure that the Agency can represent an instrument of global tourism promotion in the area of Puglia Imperiale. The creation of Local Tourist System Puglia Imperiale aims at obtaining different purposes, as established in Article 2 of the memorandum of understanding that allowed the establishment of the system (Fig.3):

$>\quad$ to promote the local identity and the excellence of the territory;

$>$ to give life to a shared strategic vision of local tourist development;

to create integrated specific packets of offer, through cooperation with tour operator and travel agencies of the territory;

$>\quad$ to promote the local resources and to commercialize the tourist products;

$>\quad$ to enhance the culture of hospitality;

$>\quad$ to contribute to the formation of new tourism businesses;

$>\quad$ to foster the employment and involvement of all local actors;

$>\quad$ to elaborate the Project of local tourist development focused on a multi-annual programming and annual operational programs;

$>\quad$ to stimulate marketing and management of Apulia destination;

$>\quad$ to facilitate tourist use of the territory strengthening the local programming, enhancing cultural, sporting and folk events;

to manage the relations with Apulia Region in order to make the best use of all the resources dedicated to tourism development.

Fig.3. The Apulian Tourism Promotion Model

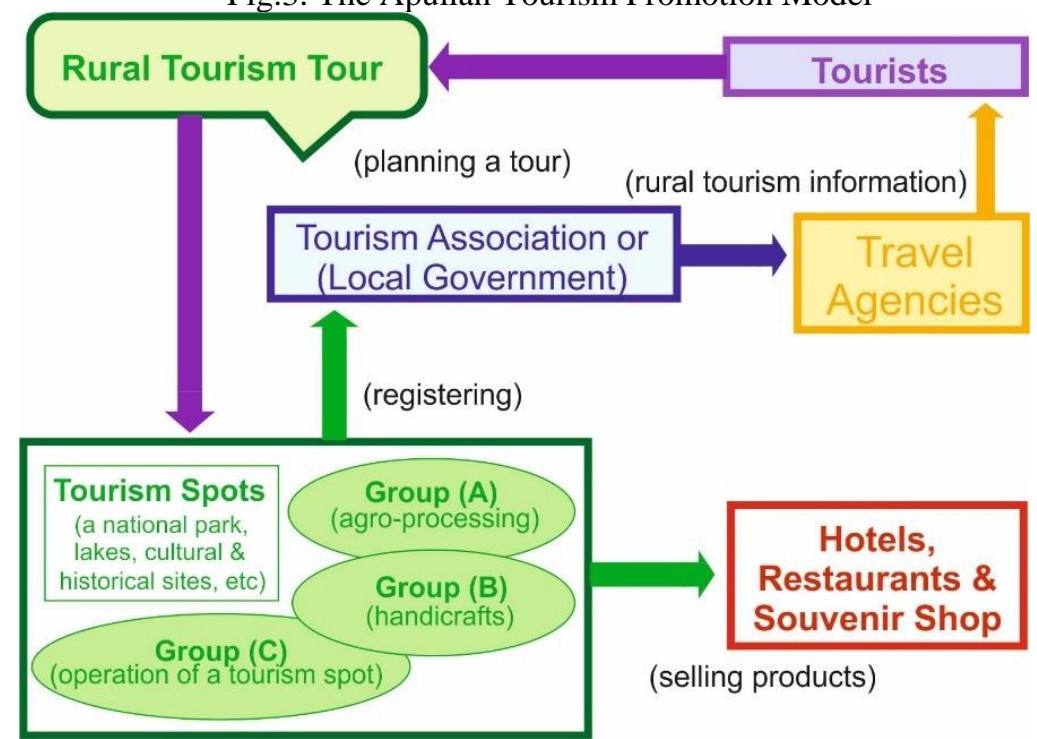

Source: Ciset - Apulia Promotion 


\subsection{The tourist quality experience of "Puglia Imperiale"}

«The Puglia Imperiale case is an example of creation of a new territorial identity brand evolved in a real tourism product, through the activity of a new Agency for destination management» (Buongiorno, 2015). At the base of this brand there is the Puglia Imperiale territory that, through the eleven municipalities distributed between Gargano and Salento, is able to propose an "integrated" (Dall'Ara \& Morandi, 2006) tourist offer. The concept of tourist system is concretized precisely in the capacity of the various local actors to be able to generate a synergy in the organization of its own offer, within a demarcated and tourist-friendly area. The territory of Puglia Imperiale, located in the heart of Puglia, includes the traces left by Emperor Federico II of Svevia, fascinating character that has marked the history of Middle Ages and that represents a territory's value that makes unique and authentic the tourist proposal of the area.

The heritage, in fact, is rich in over two hundred cultural, historicartistic and naturalistic goods such as Castel Del Monte, the ancient saltworks of Margherita di Savoia, the cathedrals of the Norman period and numerous medieval historical centers. «Puglia Imperiale looks like a city of diffused art, organized in a hospitable system, where the tourist can live the experience of a memorable travel in culture, immersing himself in the atmosphere of a thousand-year history, troubled and full of events and characters».

\section{Conclusion}

The use of experiential marketing is a founding element of the strategy to support the tourism economy of the northern Bari-Ofanto territory: the goal, in fact, is that to offer to those who come to Puglia Imperiale territory an authentic atmosphere of Apulian life, relying on hospitality, on traditions, on cultural events, on typical flavors of the territory. The use of experiential marketing in programming the tourist offer, implies a change of perspective: the new tourist is no longer guided by rationality and necessity, but by desire and emotions: the experience to be destined to the new tourist has as its objectives the involvement, the fulfillment, the strengthening of ties with other individuals thanks to the use of emotional factors.

The experience "staging" by Puglia Imperiale is a unique and exciting experience, able to involve the tourist, fascinate him and make him come back. The development of naturalistic sites, and historic artistic goods, the development of hospitality activity, the promotion of typical territory products, are actions that aim to abandon the old destination product to orientate towards a product and experiential tourism. Tourism in Apulia, in fact, is not only represented by seaside tourism, but it is also culture, nature, religion, wellness and much more. These resources are the base on which Puglia Imperiale has focused its strategy, providing the alternative to classic seaside tourism. 
To conceive the tourism product as experience, focusing on territory, hospitality, innovation, culture, through an integrated action to support the tourism economy, has been the key to success. The new tourist product and the Tourist System that is its base, have allowed, thanks to the involvement of local resources and actors, to implement a consensual and participatory planning process, promoted by Territorial Pact for North Bari Ofanto Occupation. Relying on the uniqueness of identity that the area expresses and on the possibility of combining food and wine, naturalistic and historic cultural tours, the Local Tourist System has been able to give life to the quality experience "Puglia Imperiale".

\section{References:}

1. Aaker, D. A. (2002), Brand Equity. La gestione del valore della marca. Milano: Franco Angeli.

2. Aaker, D. A., Keller, K. L. (2010), Valutazioni dei consumatori della brand extension, Giornale di Marketing, 51.

3. Aaker, D. A., Keller, K. L. (2014), Gestione della brand equity: l'impatto di molteplici estensioni di marca. Milano: Franco Angeli.

4. Addis, M (2012), Ad uso e consumo: il marketing esperienziale per il manager. Milano: Pearson.

5. Buongiono, A. (2015), Il Sistema turistico locale Puglia Imperiale. Dal marchio turistico d'area allo start-up di una Destination Management Organization. www.pugliaimperialetourism.com

6. Cicia, G., Cembalo, L., Del Giudice, T., Verneau, F. (2013), Il sistema agroalimentare e il consumatore postmoderno: nuove sfide per la ricerca del mercato, Rivista Economica Agroalimentare, 54.

7. Cinti, D. (2014), Turismo rurale e progetto di paesaggio. La Valtiberina toscana per un turismo culturale e naturale sostenibile. Milano: IBS.

8. Cresta, A., Greco, I. (2011), Luoghi e forme del turismo rurale. Evidenze empiriche in Irpinia. Milano: Franco Angeli.

9. Croce, E., Perrini, G. (2010), Il turismo enogastronomico. Progettare, gestire, vivere l'integrazione tra cibo, viaggio e territorio. Milano: Franco Angeli.

10. Douglas, M., Isherwood B. (1989), The world of goods towards an anthropology of consumption. Harmondsworth, Penguin. Tr. it., Il mondo delle cose. Oggetti, valori, consumo. Bologna: Il Mulino, 1984.

11. Keller, K. L. (2013), Conceptualizing, Measuring, and Managing Customer-Based Brand Equity. Journal of Marketing, 57(1), 1-22. doi:10.2307/1252054.

12. Keller, K. L., Busacca, B., Ostillio, M.C. (2014), Gestione e sviluppo del brand. Milano: Egea. Ed.or.: Strategic Brand Management (Keller, K. L., 2003). 
13. Lo Surdo, G. (2013), Il marketing delle nuove vacanze. Comunicazione e mezzi di promozione del turismo rurale, enogastronomico, della natura, del wellness. Milano: IBS.

14. Pine, B.J., Gilmore, J.H (2000), The experience economy. Work is theatre \& Every Business is a stage. Boston: Harward Business School Press.

15. Resciniti R. (2014), Il marketing orientato all'esperienza. L'intrattenimento nella relazione con il consumatore. Milano: Edizioni Scientifiche Italiane.

16. Rossi, A., Goetz, M. (2014), Creare offerte turistiche vincenti con Tourist Experience Design. Milano: Hoepli.

17. Srivastava, K., Shocker, A. (2011), Brand Equity: a perspective on its meanining and measurement. Cambridge, UK: Marketing Science Institute. 